\title{
PREVALENCE OF FALLS IN FIBROMYALGIA PATIENTS
}

\author{
Sandra Adolph Meireles ${ }^{1}$, Daniel Casagrande Antero ${ }^{2}$, Marciane Maria Kulczycki ${ }^{1}$, Thelma Larocca Skare ${ }^{2}$
}

\section{ABSTRACT}

Objective: To compare the risk of falls in fibromyalgia (FM) patients compared to rheumatoid arthritis (RA) patients and normal controls. Methods: We studied 60 FM, 60 RA patients and 60 controls for fall frequency in one week, one month, six months and one year. Patients were submitted to body mass index determination and balance evaluation through the Berg scale. Data on disease impact and depression were collected in FM patients through the Fibromyalgia Impact Questionnaire (FIQ) and the Beck Questionnaire. Results: FM patients had a higher frequency of falls than RA patients and control individuals in one month $(p<0.0001)$, in six months $(p<0.0001)$ and in one year $(p<0.0001)$. No relationship was found between falls and body mass index, pain or depression scores. Falls in 12 months were associated with higher FIQ values. Conclusion: FM patients fall more often than RA patients and control individuals. Level of Evidence II, Investigation of the effect of a patient characteristic on the disease outcome.

Keywords: Fibromyalgia. Postural balance. Accidental falls.

Citation: Meireles SA, Antero DC, Kulczycki MM, Skare TL. Prevalence of falls in fibromyalgia patients. Acta Ortop Bras. [online]. 2014;22(3):163-6. Available from URL: http://www.scielo.br/aob.

\section{INTRODUCTION}

Fractures caused by falls are one of the factors that prevent people with chronic illnesses to live independently. Therefore, it is necessary to better understand the risk factors in order to prevent them effectively. ${ }^{1}$ Among the risk factors there are advanced age, poor vision, impaired health in general, medications, etc. ${ }^{1,2}$ Joints abnormalities are also included. ${ }^{2}$

Fibromyalgia (FM) is a musculoskeletal disease characterized by widespread pain, but with no anatomical or physiological evidence of impairment of the locomotor apparatus. ${ }^{3}$ Fibromyalgia patients complaints are not always taken seriously due to lack of objective signs of this disease. Despite the absence of inflammatory joint damage, it has been reported that patients with FM have a higher frequency of falls. Jones et al. ${ }^{4}$ studying 34 patients with FM and 32 control individuals found 37 falls in the first group in six months, compared to only 6 in the second group.

In the present study the frequency of falls in patients with FM were analyzed by comparing them to rheumatoid arthritis patients - which have inflammatory disabilities - and healthy controls. We also aimed to assess whether falls in FM patients are related to balance impairment, depression, weakness, and body mass index. We also studied its relationship with pain in general and quality of life.

\section{MATERIALS AND METHODS}

This study was approved by the Local Ethics Research Committee and all participants included signed a free and informed consent agreeing to participate.

One hundred and eighty subjects were studied: 60 with FM and 60 with RA, having been diagnosed according to criteria of the American Rheumatology Classification Criteria for FM5 and RA,6,7 respectively, and 60 healthy controls. Participants with FM were selected according to the appointment sequence and availability to participate in the study. Those 60 patients represent all patients which were diagnosed and agreed to participate at the study, which were seen at our clinic within six months.

This sample, when compared with healthy people, had a $75 \%$ probability of detecting a difference between the two groups. RA patients and healthy controls were chosen according to the appointment sequence and paired by age and sex. Healthy controls were asked among hospital staff. Data on the three groups studied are shown in Table 1. Patients who could not stand by themselves, or had severe visual or hearing impairment, known vestibular diseases, diabetes mellitus, neuropathy, dementia, history of head trauma or secondary fibromyalgia were excluded.

In the RA group, the disease duration ranged between 8-372 months (mean $121.6 \pm 92.5$ and a median of 96 months). After obtaining demographic data, and weight and height to

All the authors declare that there is no potential conflict of interest referring to this article.

\footnotetext{
1. Physiotherapy Unit, Escola Dom Bosco, Curitiba, PR, Brazil

2. Rheumatology Unit, Hospital Universitário Evangélico, Curitiba, PR, Brazil

Work developed at Hospital Universitário Evangélico, Curitiba, PR, Brazil

Correspondence: Thelma L. Skare - Rua João Alencar Guimarães, 796, 80310-420, Curitiba, PR, Brazil tskare@onda.com.br
} 


\begin{tabular}{|c|c|c|c|c|c|}
\hline & & FM $(n=60)$ & $\mathrm{RA}(\mathrm{n}=60)$ & Control $(n=60)$ & $\mathbf{P}$ \\
\hline \multicolumn{2}{|c|}{ Mean Age (years) } & 51.809 .97 & $49.98 \quad 10.93$ & 50.3510 .31 & 0.60 \\
\hline \multicolumn{2}{|c|}{ Gender (fem/mal) } & $55 / 5$ & $55 / 5$ & $55 / 5$ & 1,0 \\
\hline \multirow{4}{*}{ BMl $\left(\mathrm{kg} / \mathrm{m}^{2}\right)$} & $<20$ & 0 & 6 & 2 & \\
\hline & $20-25$ & 21 & 16 & 23 & \\
\hline & $26-30$ & 17 & 24 & 22 & \\
\hline & $>30$ & 22 & 14 & 13 & 0,052 \\
\hline
\end{tabular}

calculate body mass index (BMI), all participants were asked to recall the number of falls in the last week, last month, last six months and last year. BMI index was calculated according to the standard formula. ${ }^{8}$ Patients were divided, according to $\mathrm{BMI}$, into four groups: lower than $20 \mathrm{~kg} / \mathrm{m}^{2} ; 21-25 \mathrm{~kg} / \mathrm{m}^{2} ; 26-30$ $\mathrm{kg} / \mathrm{m}^{2}$ and higher than $30 \mathrm{~kg} / \mathrm{m}^{2}$. (Table 1)

Falls were defined as unintentionally to reach the ground or any other lower surface, such as a chair or bed. ${ }^{9}$ All participants underwent the Berg test. ${ }^{10}$ This test is an instrument that analyzes the functional balance through common tasks, such as trying to reach for an object, move from one place to another, stand up, climb, spin, etc. and everything that involves static and dynamic balance. These tasks are scored according to a Likert scale (from zero to four), with a maximum total of 56 points. Lower scores indicate unstable balance. This instrument has $82-91 \%$ sensitivity and $70-95 \%$ specificity in assessing the risk of falls. ${ }^{11}$

RA and FM patients were asked to complete a visual analogue scale (VAS) for pain in general from zero through ten. FM patients were also submitted to a questionnaire on Fibromyalgia Impact (FIQ) for determining the impact of the disease and Beck Depression Scale. $\mathrm{FIQ}^{10}$ is a 10 items instrument that measures physical disability and severity of specific symptoms such as pain, stiffness, fatigue, disability and general well-being during the last week. The severity of each symptom is measured on a scale from zero (no symptoms) to ten (very severe symptoms). Beck depression scale ${ }^{12}$ has 21 items graded in four levels $(1=$ absent, $2=$ mild, $3=$ moderate and 4 = severe) ranging from 0-84 with higher scores denoting a more depressive status. This scale assesses symptoms that are normally present in depression, regardless of their cause. Among the evaluated items are mood, fatigue, anhedonia, health concerns, and changes in libido, among others.

Data were grouped into frequency and contingency tables. Unpaired Mann-Whitney and Kruskal-Wallis tests (for nonparametric data), and non-paired t test (for parametric data) were applied to compare numerical data tests of and chi-square test for nominal data. For correlation studies the Spearman test was used. Statistical analysis was performed using the Graph Pad Prism 4.0 software and setting significance at 1\%.

\section{RESULTADOS}

By studying the number of falls in the three samples, we find displayed in Table 2 and Figure 1 the data, which show a greater number of falls in FM patients than in controls and in RA patients. Patients with RA have more falls than the control group, but without statistical significance.

Studying the Berg values in the three groups (RA, FM and control) we found that the FM group 2/60 had values between 21-40 and 58/60 had values between 41-56; in patients with RA $1 / 60$ had values between $21-40$ and $58 / 60$ between $41-56$ and all of the control group (60/60) were in the group between $41-56(p=0.36)$.

Table 2. Number of falls in patients with fibromyalgia (FM), rheumatoid arthritis (RA) and the healthy control group.

\begin{tabular}{|c|c|c|c|c|}
\hline & FM $(n=60)$ & $R A(n=60)$ & Control $(n=60)$ & $\mathbf{P}$ \\
\hline Falls in 1 week (mean) & 0.130 .34 & $0.07 \quad 0.31$ & 0.020 .13 & 0.0332 \\
\hline Falls in 1 month (mean) & 0.651 .10 & 0.130 .50 & $0.07 \quad 0.25$ & $<0.0001$ \\
\hline Falls in 6 months (mean) & 1.653 .15 & 0.421 .15 & 0.250 .51 & $<0.0001$ \\
\hline Falls in 1 year & $2.43 \quad 3.77$ & $0.67 \quad 1.62$ & $0.55 \quad 1.35$ & $<0.0001$ \\
\hline
\end{tabular}

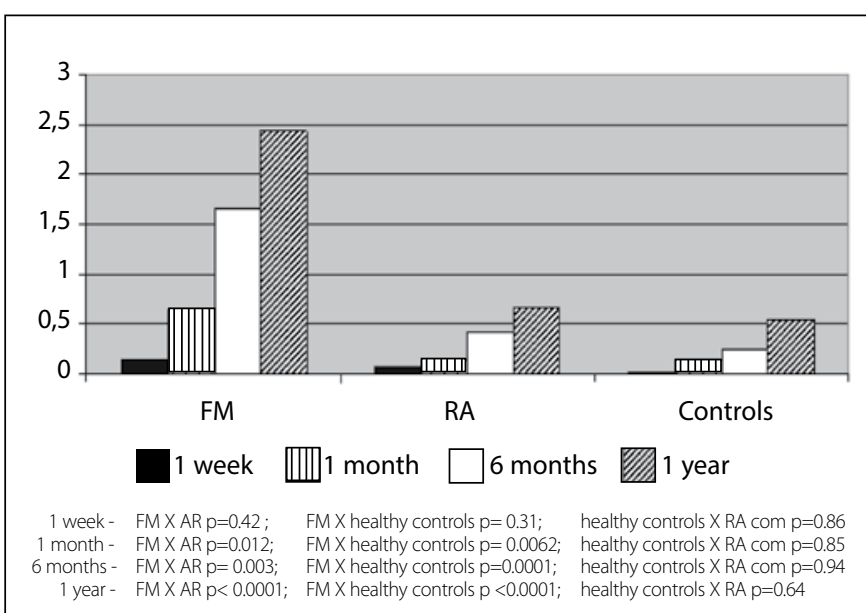

Figure 1. Mean frequency of falls (per person) of patients with fibromyalgia (FM), Rheumatoid Arthritis (RA) and healthy controls in one week, one month, six months and 1 year.

The correlation between Berg values and numbers of falls was found in the FM group at one month, six months and one year, are found in Table 3.

No influence of BMI was observed in the number of falls among the three groups. (Table 4)

Mean values of VAS for pain were $7.80 \pm 2.10$ in FM and 4.63 \pm 2.77 in RA patients $(p=0.00001)$. Analyzing the number of falls in relation to pain, Beck and FIQ in FM group, we found the results presented in Table 5 .

If we isolate the item on "feeling of weakness" from FIQ, we found that FM patients show VAS on weakness between 1 and 8.5 (mean $6.29 \pm 1.99$ ), whereas no relationship was found between sensation of weakness and number of falls in one week $(p=0.67)$; one months $(p=0.57)$ and 6 months $(p=0.24)$ or 1 year $(p=0.09)$. 
Table 3. Relationship between Berg ${ }^{10}$ scale and the number of falls in patients with rheumatoid arthritis (RA) fibromyalgia (FM) and the healthy control group.

\begin{tabular}{c|c|c|c|c|c|c|c|c}
\hline & \multicolumn{2}{|c|}{1 week } & \multicolumn{2}{c|}{1 month } & \multicolumn{2}{c|}{6 months } & \multicolumn{2}{c}{1 year } \\
\hline & $\mathbf{p}$ & Spearman $\mathbf{r}$ & $\mathbf{p}$ & Spearman $\mathbf{r}$ & $\mathbf{p}$ & Spearman $\mathrm{r}$ & $\mathbf{p}$ & Spearman r \\
\hline FM & 0.054 & -0.175 & 0.001 & -0.296 & 0.0009 & -0.299 & $<0.0001$ & -0.353 \\
\hline RA & 0.21 & -0.162 & 0.92 & 0.0012 & 0.74 & -0.042 & 0.55 & -0.07 \\
\hline Control & 0,57 & 0,074 & 0,93 & 0,010 & 0,30 & $-0,13$ & 0,05 & $-0,24$ \\
\hline
\end{tabular}

Table 4. Number of falls in patients with fibromyalgia (FM), rheumatoid arthritis (RA) and the healthy control group according to body mass index.

\begin{tabular}{c|c|c|c|c|c|c|c|c}
\hline & \multicolumn{2}{|c|}{1 week } & \multicolumn{2}{c|}{1 month } & \multicolumn{2}{c|}{6 months } & \multicolumn{2}{c}{1 year } \\
& $p$ & Spearman $r$ & $p$ & Spearman $r$ & $p$ & Spearman r & $p$ & Spearman r \\
\hline FM & 0.47 & -0.065 & 0.44 & 0.071 & 0.07 & 0.161 & 0.12 & 0.141 \\
\hline RA & 0.22 & 0.160 & 0.25 & 0.150 & 0.61 & 0.066 & 0.90 & -0.016 \\
\hline Control & 0.11 & 0.206 & 0.22 & 0.158 & 0.56 & 0.076 & 0.53 & 0.082 \\
\hline
\end{tabular}

Table 5. Correlation between falls and pain, depression and Fibromyalgia Impact Questionnaire (FIQ).

\begin{tabular}{c|c|c|c|c|c|c}
\hline & \multicolumn{2}{|c|}{ VAS (pain) } & \multicolumn{2}{c|}{ BECK } & \multicolumn{2}{c}{ FIQ } \\
\hline & $p$ & Spearman r & $p$ & Spearman r & $p$ & Spearman r \\
\hline 1 week & 0.98 & 0.002 & 0.69 & 0.051 & 0.24 & 0.15 \\
\hline 1 month & 0.60 & 0.067 & 0.68 & 0.053 & 0.11 & 0.20 \\
\hline 6 months & 0.16 & 0.180 & 0.87 & 0.020 & 0.08 & 0.22 \\
\hline 1 year & 0.018 & 0.302 & 0,87 & $-0,020$ & 0.005 & 0.35 \\
\hline
\end{tabular}

\section{DISCUSSION}

Our results demonstrate that patients with FM have a higher average rate of falls than RA patients and compared to healthy controls. The incidence of falls at 6 months was 1.75 falls/person, a value higher than that found by Jones et al., ${ }^{4}$ (1.15 falls/person). Rheumatic disease can cause falls when inducing loss of balance, muscle weakness and changes in gait pattern. Loss of Acta Ortop Bras. 2014;22(3):163-6 balance and falls have been associated with muscle weakness in RA and FM. However, in our study, balance according to Berg scale was the same in patients with RA and FM, nevertheless these two groups of patients have different fall frequencies. According to Nørregaard et al. ${ }^{13} \mathrm{FM}$ patients have about 35\% reduced muscle strength per unit area. These authors stated that this finding may be due to factors such as inactivity or neuroendocrine causes. Others have found that improvement in muscle strength provides benefits on postural balance in patients with FM. ${ }^{14}$ However, if we credit the falls only to loss of muscle strength, how is it possible to explain that the RA group have different fall frequencies than the group with FM? Pierrynowski et al. ${ }^{15}$ observed that patients with FM have a different gait pattern when compared with healthy controls. They found that patients with FM preferably propel gait using hip flexors, while normal controls use the ankle plantar flexors. The standard used by FM patients is similar to that used by healthy controls when walking quickly and this kind of gait could explain the feeling of fatigue experienced by these patients. Fatigue could be implied in the high fall frequency. Decreased ankle flexibility, decreased plantar tactile sensitivity, and strength of the plantar toes are considered contributing factors to falls of elderly people without artritis. ${ }^{16}$ Another finding by Bazzichi et al., ${ }^{17}$ who studied electromyography results, is that FM patients have a median spectral frequency, conduction velocity and fatigue index significantly lower than controls, suggesting that they may have different recruitment pattern of fibers or fiber atrophy type 2. Such changes may impair muscle relaxation and cause a motor unit activation pattern similar to that observed in patients with Parkinson's disease. The function of the auditory brainstem is also impaired in patients with $\mathrm{FM} .{ }^{18}$

In the elderly, depression is considered a significant propensity to falls in a period of 12 months. ${ }^{19}$ The underlying mechanism is not well known, but it is believed to be mediated through loss of self-confidence and anxiety in performing daily tasks. The association between depression and gait instability has been shown, as these patients require longer time and variation in the balance step. In the present study, we could not assign falls to depression in patients with FM.

We found an association between the number of falls over 12 months with FIQ and a trend for association with pain intensity, showing that falls are more common in people with greater impact of the disease, although a causal relationship cannot be inferred.

As this study is retrospective, the recovered number of falls can be overestimated in patients with FM due to the negative impact associated to this disease. Thus, further prospective studies should be performed to confirm these results.

\section{CONCLUSION}

Our results suggest that patients with FM have greater frequency of falls than RA patients and normal controls. In the study sample, no relationship could be demonstrated between falls and $\mathrm{BMI}$, depression or pain. Patients with more frequent falls in 12 months have worse quality of life. Even though this is retrospective study with all the recall bias involved in the project, we highlight the higher prevalence of falls in FM patients and it is suggested that further studies ought to be made in order to understand the pathophysiology of falls in this population. 


\section{REFERENCES}

1. Oswald AE, Pye SR, O'Neill TW, Bunn D, Gaffney K, Marshall T, et al. Prevalence and associated factors for falls in women with established inflammatory polyarthritis. J Rheumatol. 2006;33(4):690-4.

2. Smulders E, Schreven C, Weerdesteyn V, van den Hoogen FH, Laan R, Van Lankveld W. Fall incidence and fall risk factors in people with rheumatoid arthritis. Ann Rheum Dis. 2009;68(11):1795-6.

3. Arias M. Es la fibromialgia una enfermidad neurological? Neurología. 2008;23(9):593-601.

4. Jones KD, Horak FB, Winters-Stone K, Irvine JM, Bennett RM. Fibromyalgia is associated with impaired balance and falls. J Clin Rheumatol. 2009;15(1):16-21.

5. Dadabhoy D, Clauw DJ. The fibromyalgia syndrome. In: Klippel JH, Stone JH, Crofford LJ, White PH. editors. Primer on the rheumatic diseases. 13th ed. New York: Springer Science; 2008. p. 87-93.

6. Arnett FC, Edworthy SM, Bloch DA, McShane DJ, Fries JF, Cooper NS, et al. The American Rheumatism Association 1987 revised criteria for the classification of rheumatoid arthritis. Arthritis Rheum. 1988;31(3):315-24.

7. Klippel JH, Dieppe PA. Selected measures for outcome assessment of rheumatic diseases. In: Klippel JH, Dieppe PA, editors. Rheumatology. 2nd ed. London: Mosby; 1998. p. 1-12.

8. Department of Health and Human Services, National Institutes of Health, Obesity Education Initiative. BMI Calculator. Disponível em: http://www.nhlbisupport. com/bmi/. (acessado em 02 fevereiro 2010).

9. Kaz Kaz H, Johnson D, Kerry S, Chinappen U, Tweed K, Patel S. Fall-related risk factors and osteoporosis in women with rheumatoid arthritis. Rheumatology (Oxford). 2004;43(10):1267-71.
10. Marques AP, Santos AMB, Assumpção AMLA, Lage LV, Pereira CAB. Validation of the Brazilian version of the Fibromyalgia Impact Questionnaire (FIQ). Rev Bras Reumatol. 2006; 46(1):24-31.

11. Miyamoto ST, Lombardi Junior I, Berg KO, Ramos LR, Natour J. Brazilian version of the Berg balance scale. Braz J Med Biol Res. 2004;37(9):1411-21.

12. Beck AT, Ward CH, Mendelson M, Mock J, Erbaugh J. An inventory for measuring depression. Arch Gen Psychiatry. 1961;4:561-71.

13. Nørregaard J, Bülow PM, Danneskiold-Samsøe B. Muscle strength, voluntary activation, twitch properties, and endurance in patients with fibromyalgia. J Neurol Neurosurg Psychiatry. 1994;57(9):1106-11.

14. Tomas-Carus P, Gusi N, Häkkinen A, Häkkinen K, Raimundo A, Ortega-Alonso A. Improvements of muscle strength predicted benefits in HRQOL and postural balance in women with fibromyalgia: an 8-month randomized controlled trial. Rheumatology (Oxford). 2009;48(9):1147-51.

15. Pierrynowski MR, Tiidus PM, Galea V. Women with fibromyalgia walk with an altered muscle synergy. Gait Posture. 2005;22(3):210-8.

16. Menz HB, Morris ME, Lord SR. Foot and ankle risk factors for falls in older people: a prospective study. J Gerontol A Biol Sci Med Sci. 2006;61(8):866-70.

17. Bazzichi L, Dini M, Rossi A, Corbianco S, De Feo F, Giacomelli C, et al. Muscle modifications in fibromyalgic patients revealed by surface electromyography (SEMG) analysis. BMC Musculoskelet Disord. 2009;10:36

18. Rosenhall U, Johansson G, Orndahl G. Eye motility dysfunction in chronic primary fibromyalgia with dysesthesia. Scand J Rehabil Med. 1987;19(4):139-45.

19. Sai AJ, Gallagher JC, Smith LM, Logsdon S. Fall predictors in the community dwelling elderly: a cross sectional and prospective cohort study. J Musculoskelet Neuronal Interact. 2010;10(2):142-50. 